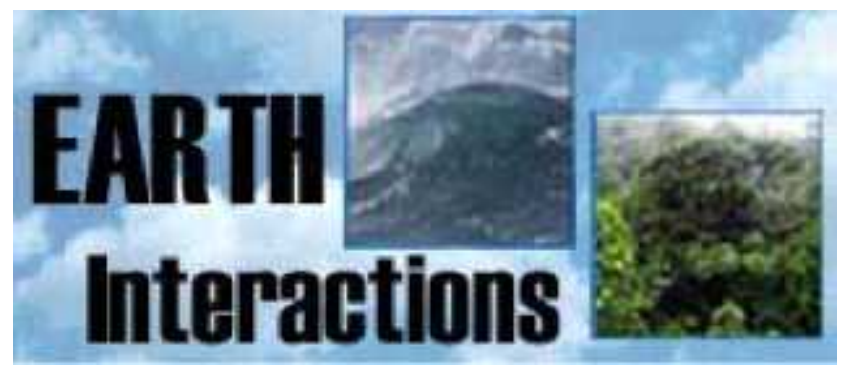

Copyright $\odot$ 2007, Paper 11-015; 6,455 words, 8 Figures, 0 Animations, 1 Table. http://EarthInteractions.org

\title{
Hydrological Impacts of Deforestation on the Southeast Tibetan Plateau
}

\section{Xuefeng Cui*}

Max Planck Institute for Meteorology, Hamburg, Germany; Institute of Atmospheric Physics, Chinese Academy of Science, Beijing, China; and Department of Geography, University of Liverpool, Liverpool, United Kingdom

\section{Hans-F. Graf}

University of Cambridge, Cambridge, United Kingdom

\section{Baerbel Langmann}

Institute of Geophysics, University of Hamburg, Hamburg, Germany

\section{Wen Chen and Ronghui Huang}

Institute of Atmospheric Physics, Chinese Academy of Science, Beijing, China

Received 1 November 2006; accepted 29 May 2007

ABSTRACT: The hydrological impact of forest removal on the southeast Tibetan Plateau during the second half of the last century is investigated in this study using an atmospheric general circulation model. The effects of deforestation are investigated by examining the differences between the forest replace-

* Corresponding author address: Xuefeng Cui, Department of Geography, University of Liverpool, Roxby Building, Liverpool L69 7ZT, United Kingdom.

E-mail address: x.cui@liverpool.ac.uk 
Earth Interactions - Volume 11 (2007) • Paper No. 15 • Page 2

ment and control experiments. Model results demonstrate that deforestation of the southeast Tibetan Plateau would influence the local and the remote climate as well. It would lead to decreased transpiration and increased summer precipitation in the deforested area and a wetter and warmer climate on the Tibetan Plateau in summer. This may produce more runoff into the rivers originating from the Tibetan Plateau and worsen flooding disasters in the downstream areas. The numerical experiments also show that deforestation would remotely impact Asian climate, and even global climate, although the statistical significance is small. A strong drought is found at middle and lower reaches of the Yellow River, where livelihoods and economics have suffered from recent droughts. Ecosystem research on the Tibetan Plateau is a relatively new topic and needs further interdisciplinary investigation.

KEYWORDS: Deforestation; Southeast Tibetan Plateau; GCM; Hydrology

\section{Introduction}

Large-scale land cover changes in general can result in dramatic climate changes (e.g., Charney 1975) through biogeophysical effects (Brovkin et al. 2004) or via biogeochemical feedbacks (Sitch et al. 2005), for example, affecting hydrological cycle intensity (e.g., Avissar and Werth 2005) or atmospheric chemistry (e.g., Ganzeveld and Lelieveld 2004). During the last two decades, tropical deforestation (e.g., Henderson-Sellers and Gornitz 1984), such as in the Amazon (e.g., Shukla et al. 1990), Africa (e.g., Snyder et al. 2004), and Southeast Asia (e.g., Xue et al. 2004; Mabuchi et al. 2005a; Mabuchi et al. 2005b), was studied extensively with atmospheric general circulation models (GCMs; e.g., Werth and Avissar 2002), regional climate models (e.g., Baidya Roy and Avissar 2002; Sen et al. 2004), satellite data analysis (e.g., Negri et al. 2004; Linderman et al. 2005), and observational field campaigns (e.g., Avissar et al. 2002). These studies reveal that deforestation usually results in higher surface albedo (Myhre and Myhre 2003; Hales et al. 2004) and lower surface roughness (Sen et al. 2004) in their study areas. This leads not only to a decrease in evapotranspiration and an increase of surface temperature locally, but can also impact global hydrometeorology through teleconnections (e.g., Avissar and Werth 2005). However, the overall net effect of deforestation is still hard to evaluate since it is too small to discern from natural climate variability (Sitch et al. 2005). Deforestation is not restricted only to the Tropics (e.g., Betts 2000) and regional responses are highly variable. It might vary from one location to another (e.g., Govindasamy et al. 2001) or in different years (e.g., Pan et al. 1999) or with different climatic scenarios (e.g., $2 \times \mathrm{CO}_{2}$; Costa and Foley 2000; Zhang et al. 2001).

The southeast Tibetan Plateau (SETP) refers to the geographic region that encompasses the southeast Tibet Autonomous Region (TAR), northern Yunnan, western Sichuan, southwest Gansu, and southeast Qinghai (Figure 1). It is a huge mountainous area with elevation ranging from $3000 \mathrm{~m}$ to more than $7000 \mathrm{~m}$ above sea level (ASL). Figure 2 demonstrates that major forest cover changes have occurred in this region during the second half of the twentieth century. Figure 2a is obtained from the International Satellite Land Surface Climatology Project (ISLSCP) Initiative II data collection (Klein Goldewijk 2001) and it shows that, in 1950, the steep slopes of the SETP were mostly covered by coniferous forest, 


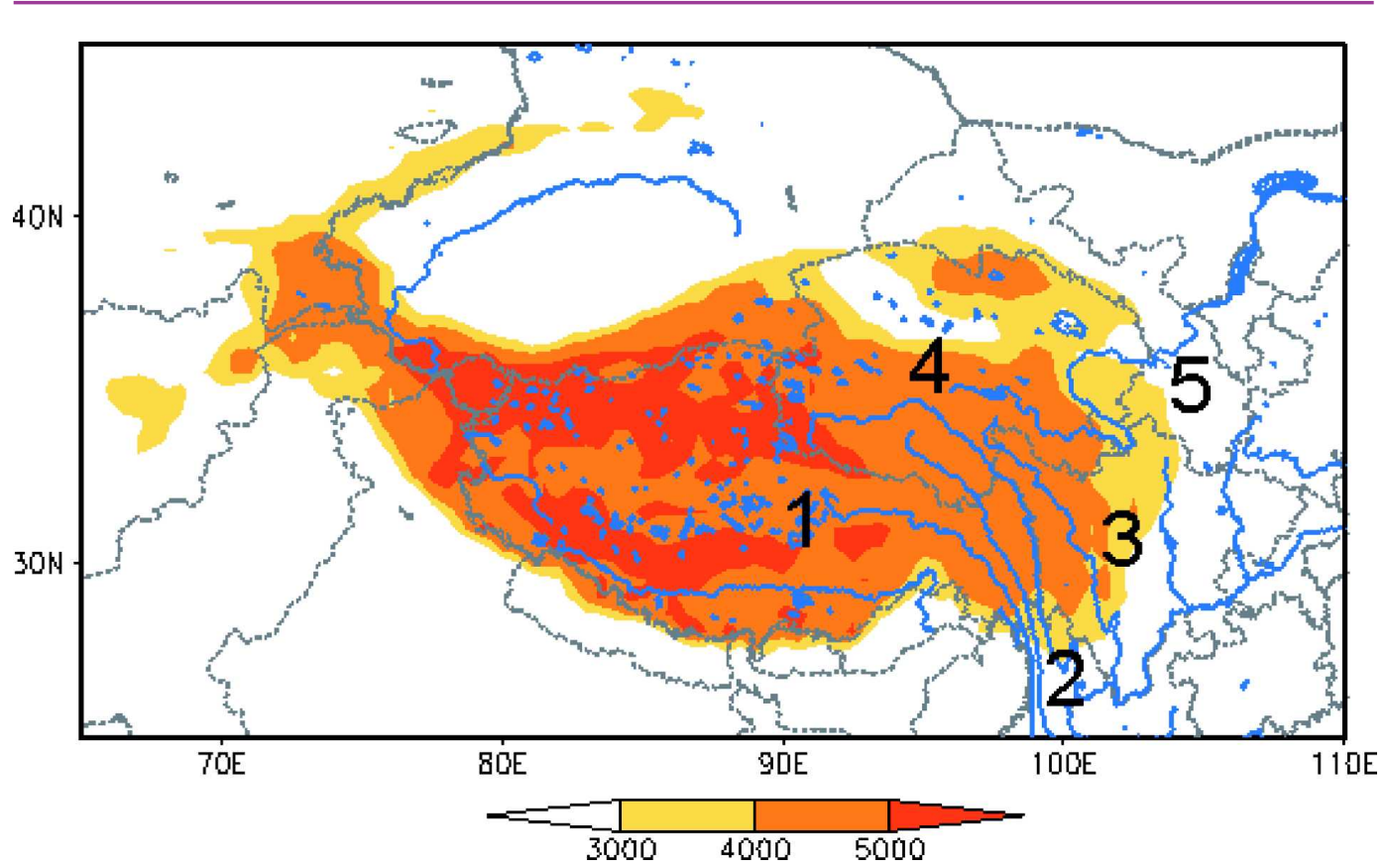

Figure 1. Geographic location of the Tibetan Plateau is shown as the shaded region where topography is higher than $3000 \mathrm{~m}$. Gray dashed contour lines show the boundaries between countries or the provinces in China. The southeast Tibetan Plateau covers parts of 1) the Tibet Autonomous Region, 2) Yunnan province, 3) Sichuan province, 4) Qinghai province, and 5) Gansu province. Blue contour lines or circles represent the rivers or lakes in China.

which contained China's largest forest resource (Studley 1999). However, most of the forest had been cleared by the year 1992/93, as shown in Figure 2b derived from 1-km Advanced Very High Resolution Radiometer (AVHRR) data (available from U.S. Geological Survey 2001). Forest inventories also revealed that deforestation in this area began in the 1950s and accelerated in the 1960s (Studley 1999; Houghton and Hackler 2003), reducing the forest area from about $121 \times 10^{6}$ ha to $24 \times 10^{6}$ ha (Fang et al. 2001) and turning into cropland and buildups. In the TAR, forest cover decreased from 55\% to $30 \%$ and in Sichuan from $30 \%$ to $6.5 \%$ during last $50 \mathrm{yr}$ (Studley 1999). The major factors responsible for forest loss in the SETP have been unsustainable logging practices (Houghton and Hackler 2003), agricultural use, and urbanization (Liu et al. 2005).

The forests of the SETP fulfill a crucial hydrological function both in and beyond China. One-third of the world's population lives along the rivers that originate on the Tibetan Plateau (TP) and flow through the SETP, including the Huanghe, Yangtze, Mekong, Salween, etc. Deforestation in the SETP may impair forest functions of safeguarding watersheds and river flow (Houghton and Hackler 2003). For example, deforestation in the upper reaches of the Yangtze basin in China led to a reduction of forest cover from $22 \%$ of the total area in 1957 to only $10 \%$ in 1986. As a result, soil erosion from the upper reaches and sediment 

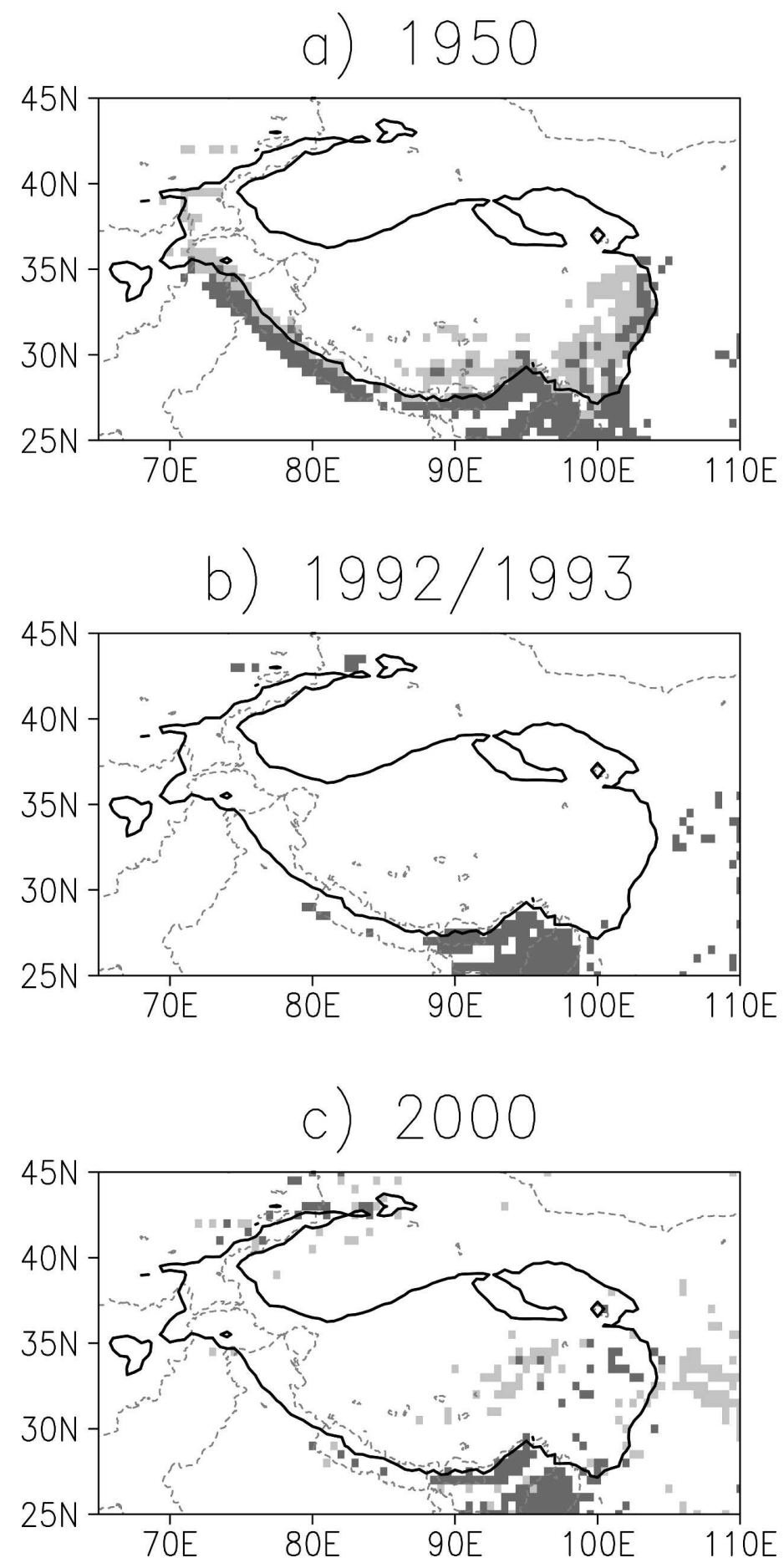

Figure 2. Forest cover on and adjacent to the Tibetan Plateau of (a) 1950, (b) 1992/93, and (c) 2000. Dataset information can be found in the text. The contour line at $3000 \mathrm{~m}$ ASL shows the location of the Tibetan Plateau. Light gray represents boreal coniferous forest, while dark gray represents warm broadleaf forest. 
redistribution in the middle and lower reaches have intensified. These effects might have contributed to the most severe flood in Chinese history in the Yangtze valley in 1998, affecting 223 million people and causing more than $\$ 36$ billion (U.S.) in economic loss (Zhang et al. 2000).

In 1998, the Chinese central government recognized the disastrous consequences of forest degradation resulting in the loss of biodiversity, unacceptable levels of soil erosion, and catastrophic flooding. A new forest policy called the Natural Forest Conservation Program (NFCP) was implemented in 1998 (Zhang et al. 2000). The Chinese national forest survey shows that after 1980 the forest cover in China has already increased by about $20 \times 10^{6}$ ha as the result of plantations, although the natural forests continued to decline (Houghton and Hackler 2003). Figure $2 \mathrm{c}$ shows the forest cover, including natural forest as well as plantations, over the TP region in the year 2000 taken from the Global Land Cover 2000 database (GLC2000 released in 2003 at http://www.gvm.jrc.it/glc2000/). Comparison with Figure $2 \mathrm{~b}$ reveals two reforestation centers, one in the east of Sichuan along the Yangtze River valley and another in the center of the TAR. Reforestation of the eroded semidesert landscape of the SETP might be extremely difficult but still appears to have a huge potential (Miehe et al. 2003). Experimental evidence shows that the southern TAR can be reforested with indigenous tree species without irrigation if grazing is excluded (Miehe et al. 2003).

To the Chinese central government and local stakeholders, it is essential to find out the possible hydrological impact of deforestation/reforestation locally and more importantly its remote impact on downstream areas. Sharma et al. (Sharma et al. 2000) used a water balance and a distributed deterministic modeling approach to analyze the hydrological sensitivity to different projected land use scenarios in the Kosi basin, located in the mountainous area of the central Himalayas. They found that runoff would decrease if the whole basin were covered by forest areas below $4000 \mathrm{~m}$, while it would increase in the case of possible maximum conversion of forest into agricultural land under contemporary climate conditions. To the authors' knowledge, there is no study so far investigating the hydrological impact of the deforestation at the SETP either locally or remotely.

Experiences from tropical deforestation studies show that model simulations are relevant tools for such studies as reviewed above. Despite high uncertainties existing in general circulation model (GCM) simulations of climate on the TP, they are useful tools, for example, to investigate the sensitivity of global climate to the TP's elevation (e.g., Broccoli and Manabe 1992). Cui et al. (Cui et al. 2006, hereafter CUI2006) first simulated the climate impact of anthropogenic land cover change on the TP with an atmospheric GCM (AGCM), and they found that it exerts a warmer and drier climate on the TP. Anthropogenic land cover changes produce a possible modification of the Asian monsoon intensity as well. Deforestation is not included in their experiment; however, it is suspected to have a significant hydrological influence like that in the Tropics. In this study, the same AGCM as CUI2006 was run with deforestation scenarios of the southeast Tibetan Plateau. Questions of this study include the following: 1) What kind of hydrological responses are simulated by the model to the forest removal on the SETP? 2) Do these changes correspond to the available observations? 3) What hydrological implications on the downstream areas can we draw? To answer these questions, the paper is arranged as follows: section 2 introduces the model and experimental 
Earth Interactions - Volume 11 (2007) - Paper No. 15 • Page 6

design; section 3 analyzes the impact of deforestation on the TP and Asian climate; and a discussion and summary will be given in section 4 .

\section{Model and experiments}

\subsection{Model introduction}

The most recent version of the Max Planck Institute for Meteorology atmospheric general circulation model, ECHAM5 (Roeckner et al. 2003), is used in this study. The previous version, ECHAM4, has been applied to study the sensitivity of the local and global climate to deforestation and reforestation in the Mediterranean region at T42L19 resolution (Duemenil Gates and Liess 2001). ECHAM5 performs better than ECHAM4 with implementation of new parameterizations, especially of surface albedo in the Himalayan/Tibetan area (Roesch and Roeckner 2006; Hagemann et al. 2006). ECHAM5 has been used to simulate the effects of land cover change on the TP at T63L19 resolution (CUI2006). With 19 levels in the vertical, higher horizontal resolution does not lead to a more realistic climate simulation (Roeckner et al. 2006). Although inferior to T63L31, T63L19 is still applied in this study for saving central processing unit (CPU) time. It corresponds to a grid size of about $1.875^{\circ}$, approximately $200 \mathrm{~km}$ in latitude and $150 \mathrm{~km}$ in longitude in the TP region. More details of ECHAM5 can be found from the papers cited here and also at the homepage of the model (http://www.mpimet.mpg.de/en/ wissenschaft/modelle/echam.html). The capacity of ECHAM5 to simulate the atmospheric circulation and global climate has been evaluated and documented in many studies (e.g., see special section of Journal of Climate, 2006, Vol. 19, No. 16). CUI2006 also evaluated its representation of the major climate features in the Asian region and found that ECHAM5 reproduces reasonably well the seasonal shifts of the monsoon rainfall belt as well as the near-surface temperature.

\subsection{Experimental design}

A control experiment " $C$ " has been performed with the realistic land surface conditions. It is the same as the control run in CUI2006 so only some major characteristics are mentioned here. The model is integrated for $22 \mathrm{yr}$ driven with climatological global sea surface temperature (SST) and sea ice averaged over the period 1978-94 as used for the Atmospheric Model Intercomparison Project 2 (AMIP2; Gates et al. 1999) to eliminate additional interannual variability. The atmospheric variability represented in such integrations is generally less than that in simulations with interannually varying boundary conditions of SST and sea ice (Bengtsson et al. 1996). This suppresses important interactions between deforestation and hydroclimatic processes, considerably simplifying the detection of land cover teleconnections (Avissar and Werth 2005). The last 10-yr averages are analyzed here, discarding the first $12 \mathrm{yr}$ needed for model spinup.

An experiment, named " $F$ " for forest, has been conducted by replacing the current land surface in the SETP with forest as found in 1950 (shown as Figure 2a), leaving other parameters identical to those in experiment C. In ECHAM5 the surface ecosystem types and related surface parameters are prescribed, including 
Earth Interactions • Volume 11 (2007) - Paper No. 15 • Page 7

background surface albedo, surface roughness length due to vegetation, fractional vegetation cover $\left(C_{v}\right)$, and leaf area index (LAI) for the growing and dormant season, forest coverage, and plant-available and total soil water holding capacity (Table 1; Hagemann 2002). To simplify experiment F, a model grid point that is declared as forest covered is assigned with the surface parameters of boreal coniferous forest. This approximation may not completely represent the reality of historic forest changes in this region. It should not, however, hinder the ability of this study to qualitatively investigate the influences of deforestation in this region.

To visualize the differences of surface characteristics prescribed in the model between the two scenarios $\mathrm{C}$ and $\mathrm{F}$, several surface parameters are shown in Figure 3. Figures $3 \mathrm{a}-\mathrm{d}$ demonstrate decreasing forest area, increasing background surface albedo, generally increasing plant-available soil water holding capacity, and volumetric wilting point, respectively. In addition, decreasing surface roughness length due to vegetation $(\sim 1 \mathrm{~m}$; Table 1$)$ is negligible compared to the surface roughness length due to orographic variations $(\sim 20 \mathrm{~m})$. A full annual cycle of fraction of vegetation $\left(C_{v}\right)$ and LAI are implemented in ECHAM5 as well, which is thought to improve the seasonality of surface evaporation calculated by the GCM (van den Hurk et al. 2003). Figure 4 shows the changes of LAI and fractional vegetation cover due to deforestation. LAI decreases in all four seasons since forest in the F scenario is cleared and replaced with grassland, cropland, and built-up areas in the $\mathrm{C}$ scenario. The maximum decreases appear in winter and spring when the grassland and cropland cannot survive due to low temperatures in this region. Correspondingly, the fractional vegetation cover also decreases dramatically in these two seasons, while it increases in summer and autumn.

Experiment $\mathrm{F}$ is integrated for $15 \mathrm{yr}$ starting from the equilibrium conditions of the control run (12th year) with the average of the last $10 \mathrm{yr}$ analyzed. The differences of scenario $\mathrm{C}$ minus scenario $\mathrm{F}$ are assumed to represent the impact of deforestation at the SETP. A "Paired Difference Test" (von Storch and Zwiers 1999) $t$-test method is applied to test the statistical significance of the two nonindependent scenarios. Statistical significance is determined using boreal seasonal [December-February (DJF), March-May (MAM), June-August (JJA), September-November (SON)] or annual rather than monthly averages to include less of the year-to-year variability (Bonan 1997). Each year of model output represents one seasonal or annual "sample." The analyzed number of both experiments (each $10 \mathrm{yr}$ ) means that there are only nine degrees of freedom when testing for the difference between two means with the method applied here.

Table 1. Surface parameters for major land cover types on the southeastern Tibetan Plateau: background surface albedo $\alpha$, surface roughness length due to vegetation $Z_{0, v e g}$, fractional vegetation cover $C_{v}$, LAl for the growing $(g)$ and dormancy seasons $(d)$, forest ratio $C_{f}$, plant-available soil water holding capacity $W_{\text {ava }}$, and the VMP (from Hagemann 2002).

\begin{tabular}{lcccccccccc}
\hline $\begin{array}{c}\text { Global } \\
\text { ecosystems legend }\end{array}$ & Albedo $\alpha$ & $Z_{\text {O,veg }}(\mathrm{m})$ & $C_{v, g}$ & $C_{d v, d}$ & $\mathrm{LAI}_{g}$ & $\mathrm{LAI}_{d}$ & $C_{f}$ & $W_{\text {ava }}(\mathrm{m})$ & $\mathrm{VMP}$ \\
\hline Conifer boreal forest & 0.13 & 1 & 0.52 & 0.52 & 6.0 & 6.0 & 0.46 & 0.14 & 0.33 \\
Crops, crass, shrubs & 0.19 & 0.1 & 0.65 & 0.33 & 2.7 & 0.4 & 0.0 & 0.53 & 0.46 \\
Urban, buildups & 0.2 & 2.5 & 0.0 & 0.0 & 0.0 & 0.0 & 0.0 & 0.0 & 0.48 \\
\hline
\end{tabular}



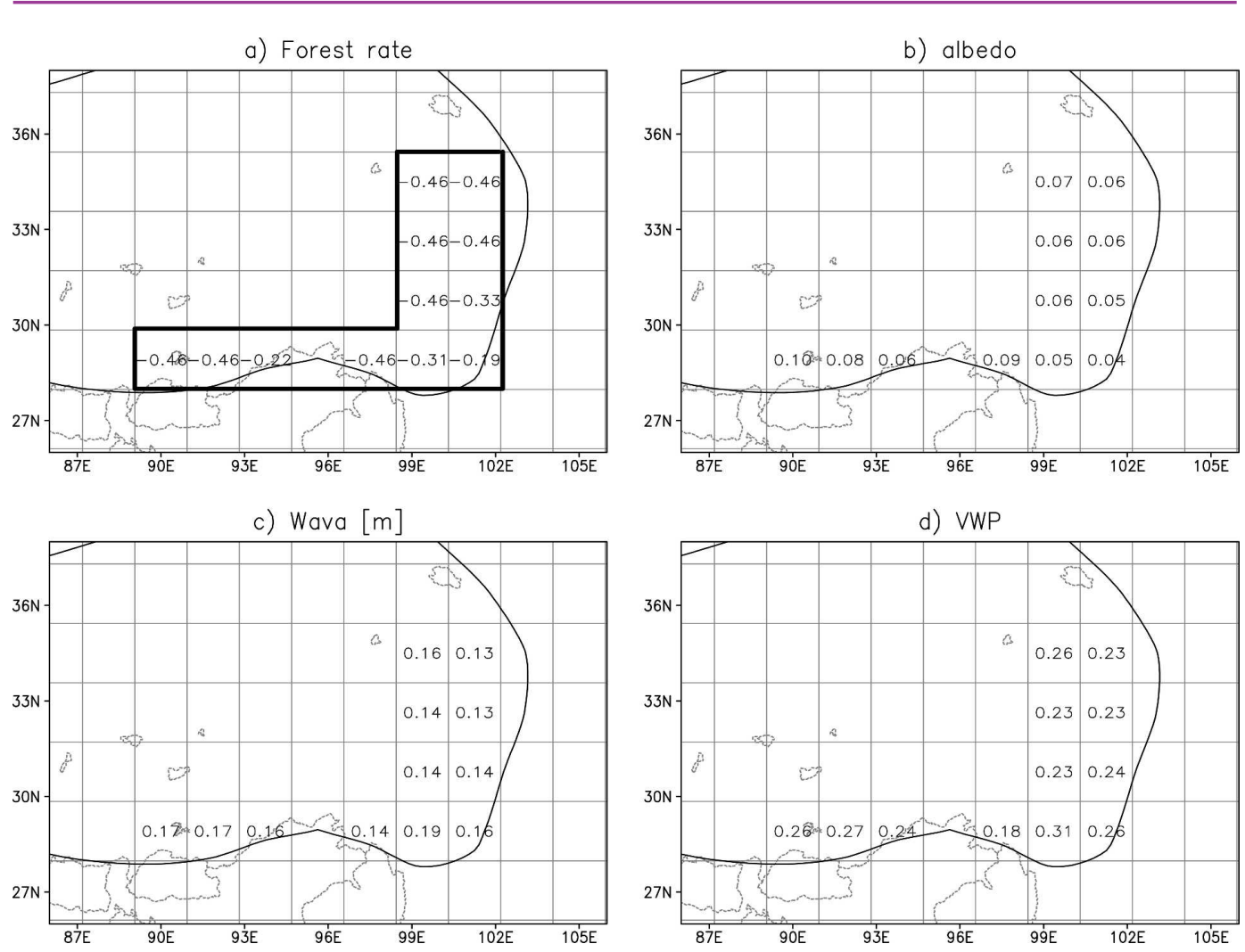

Figure 3. Differences of land surface parameters between forest and current scenario (current forest) including (a) forest coverage, (b) background albedo, (c) plant-available soil water holding capacity $\left(W_{\text {ava }}\right)$, and (d) volumetric wilting point (VWP). The black thick rectangle in (a) denotes deforested area for later area average calculation. The solid black contour lines show the height of $3000 \mathrm{~m}$ ASL.

\section{Model results}

\subsection{Regional impacts}

To reveal the local impact of deforestation on the climate at SETP, Figure 5 shows the changes of surface parameters averaged from the deforested area indicated in Figure 3a. In ECHAM5, the grid-mean surface albedo depends on the specific background surface albedo, a specific snow albedo (function of temperature), the area of the grid cell covered with forest, the snow cover on the ground (function of snow depth and slope of terrain), and the snow cover on the canopy (Roesch and Roeckner 2006). Although the background albedo is prescribed to generally increase due to deforestation (Figure 3b), the surface albedo increased mostly during the winter half-year (Figure 5a). The negligible changes of albedo in summer due to deforestation in SETP need to be verified by observational experiments in future studies, since this might lead to different hydrological influence in this area. Because of its topographic character, the plateau surface absorbs a large amount of solar radiation energy and undergoes dramatic seasonal 
Earth Interactions - Volume 11 (2007) - Paper No. 15 • Page 9

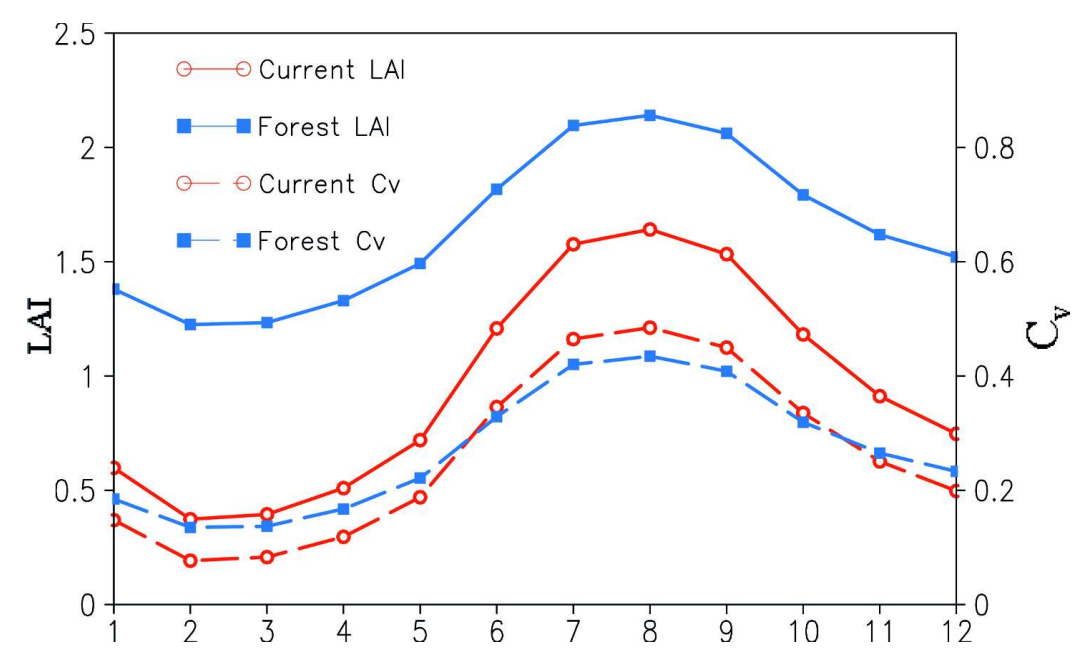

Figure 4. Seasonal variations of the area average of LAI (solid line) and vegetation fraction ( $\mathrm{Cv}$; dashed line) on the southeast Tibetan Plateau for the current (red; circle) and forest (blue; square) scenarios.

changes of surface heat and energy fluxes (e.g., Ma et al. 2006). In the current GCM experiment, it is impossible to simulate accurately the surface heat fluxes over such a heterogeneous landscape. Negative radiative forcing of deforestation (e.g., Myhre and Myhre 2003) is only found during April and May in our experiment (Figure 5b). The net surface radiation (NSR; sum of net surface shortwave and longwave radiation) remains unchanged elsewhere. The radiative forcing is not linear with surface albedo changes and is dependent on the snow distribution (Myhre and Myhre 2003), which is not able to be represented accurately in the current GCM over the TP. On the TP, the sensible heat flux dominates in the wintertime with a maximum in the spring (Figure 5c) when the surface temperature increases (Figure 5e). It starts to decrease while latent heat flux increases in the summer when the rainy season starts (Figure 5f). The latent heat flux can even become larger than sensible heat flux when the evaporation reaches its maximum in summer (Figure 5d). The sensible heat flux becomes larger in the deforested area, especially in February and March. The evaporation is generally less in the deforested area throughout the whole year, which will lead to less surface latent heat flux. Only a slight cooling is found during the winter shown from the 2-m surface temperature, which is corresponding to the changes of surface energy budget (NSR plus sensible heat flux and latent heat flux; figure not shown). However, the changes of latent heat flux might exert strong influence on the horizontal and convective circulations of the atmosphere and, consequently, change the distribution of precipitation. The mean precipitation in the deforested area increases in the summer half-year from April to August but decreases in the winter half-year except in September and October (Figure 5f). The changes of precipitation might imply changes of regional convective circulation, which need to be addressed with high-resolution regional model simulation (Cui et al. 2007) in the future other than the current coarse GCM experiment. The wetter summer trends found here agree with the station observations (Niu et al. 2004) and tree-ring 

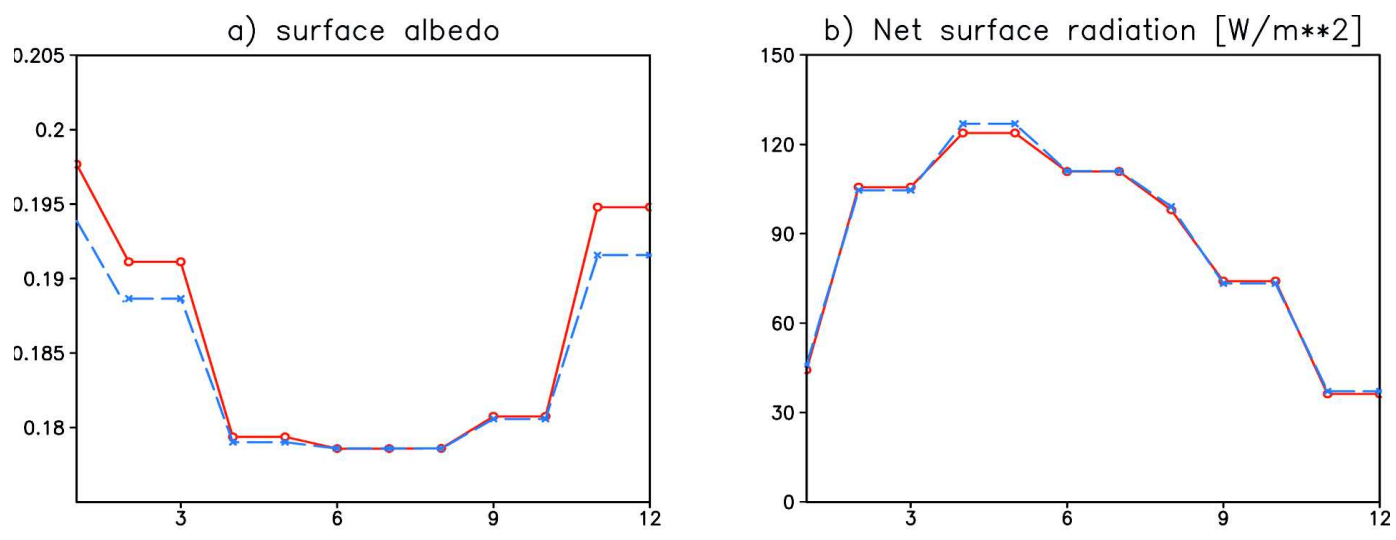

c) Sensible heat flux $[\mathrm{W} / \mathrm{m} * * 2]$

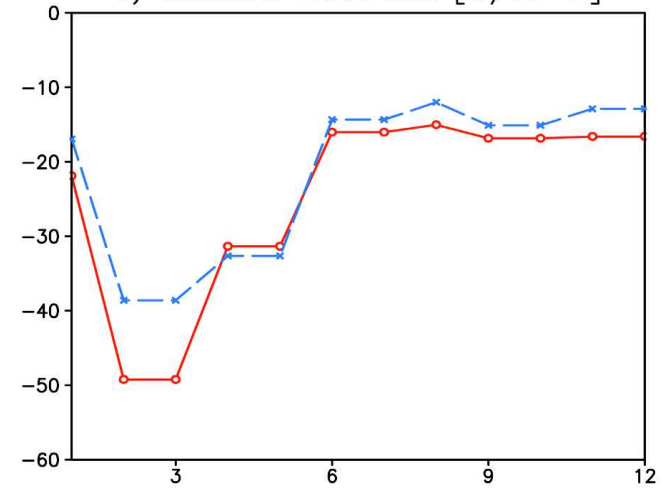

d) Evap. $[\mathrm{mm} /$ day $]$

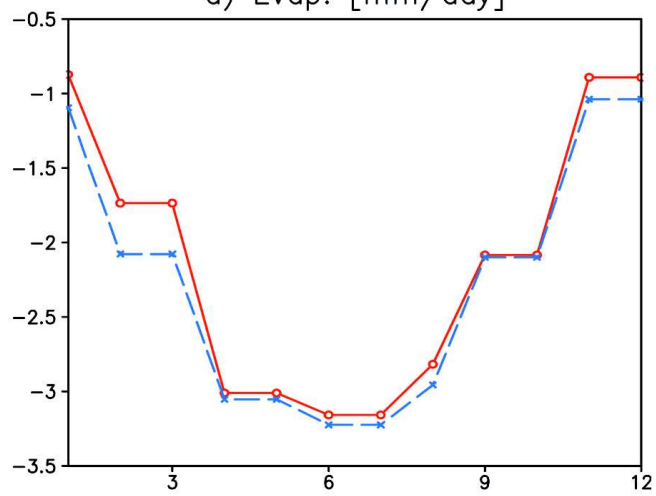

e) Temp. $2 m[K]$
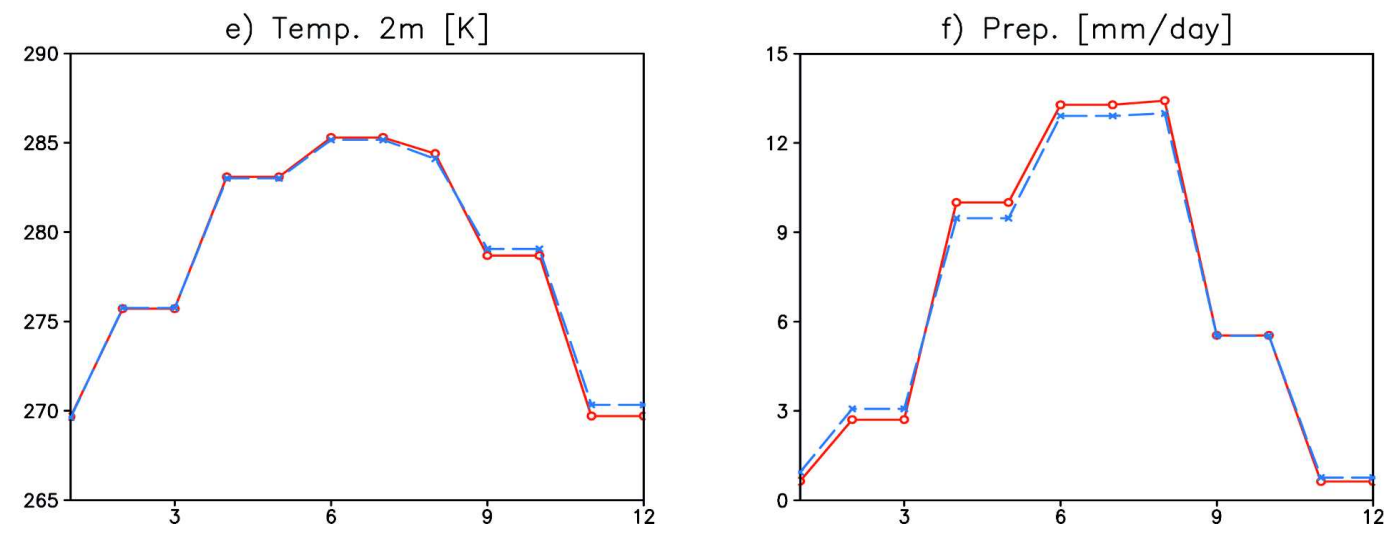

Figure 5. Annual cycle of 10-yr mean surface parameters from the current (solid) and forest (dotted) scenarios conducted by ECHAM5 for (a) surface albedo, (b) NSR, (c) sensible heat flux, (d) surface evaporation, (e) 2-m air temperature, and $(f)$ daily precipitation.

records for the period of 1961-90 (Braeuning and Mantwill 2004). Together with decreased evaporation (Figure 5d), the surface runoff increases, influencing the discharge of the rivers originating from the TP. In total, the precipitation in the deforested area increases $\left(+30.5 \mathrm{~mm} \mathrm{yr}^{-1}\right)$ while surface evaporation gets weaker 
Earth Interactions • Volume 11 (2007) • Paper No. 15 • Page 11

$\left(-47.9 \mathrm{~mm} \mathrm{yr}^{-1}\right)$, thus leading to an increase of surface runoff of $95 \mathrm{~mm} \mathrm{yr}^{-1}$, an amount of $3.9 \times 10^{10} \mathrm{~m}^{3}$ for the whole area. Such changes of river discharge might have an influence on the increasing frequency of flooding downstream (e.g., Zhang et al. 2000).

\subsection{Impacts on Asian climate}

The TP plays an important role in forming and inducing variations of regional weather and climate in East and South Asia, as well as of the Northern Hemisphere atmospheric circulation in general (e.g., Ye and Gao 1979). CUI2006 concluded that anthropogenic land cover changes over the TP intensify the Indian monsoon and weaken the east China monsoon, while leading to warmer and drier climate at the TP. The remote impact of deforestation at SETP on the Asian climate system, especially the hydrological impact in China, will be addressed in more detail in this section. The analyses are conducted on a four-season basis to capture the seasonal variations.

Figure 6 shows the spatial distribution of differences of seasonal mean nearsurface temperature between scenarios $\mathrm{C}$ and $\mathrm{F}$. In winter, a zonal band of cooling stretches in the midlatitudes from the Ural Mountains toward Japan with amplitudes well over $1 \mathrm{~K}$. Significant warming is found over northeast Siberia. The TP cools slightly, however, at marginal significance, while west India, southwest China, the tropical Indian Ocean, and the southern tip of the Malaysian peninsula warm significantly despite the fixed SSTs. In spring few significant anomalies occur. Some warming tendency in midlatitude central Siberia and northeast India is seen as well as cooling over south China. Summer shows mainly significant warming over west Siberia and contrasting anomalies between the western (cold) and eastern (warm) TP. Fall exhibits strong significant warming over easternmost Siberia and cooling centered over northeast China, southeast Siberia, and the eastern TP as well as warming over India, the Kaukasus region, and southern Southeast Asia (Malaysia and Indonesia).

The Asian region is characterized by its monsoonal climate. Most of the annual rainfall occurs in summer and is mainly related to the moisture transported from tropical or ocean regions (for a review, see Webster et al. 1998). Figure 7 shows the seasonal precipitation changes, including snowfall, due to deforestation on the SETP. In winter, drying is found at the cooling area in the midlatitudes (Figure 6a) from the Ural Mountains toward Japan. Southern TP and the Indochina Peninsula get significantly drier, while more rainfall falls on the Maritime Continent with marginal significance. In spring, the most significant changes are found in eastern China, with a "wet-dry" oscillation from the southern coastal area extending to south Siberia through north China. The increase of precipitation in the upper reach of the Yangtze River might increase the risk of flood disaster in spring. When summer monsoonal rainfall moves to the Asian continent, it generally decreases, particularly in the middle and lower reaches of the Yangtze River and Siberia. The TP and its southeast tip get significantly wetter and so does the area from north China to Japan. In autumn, a significant drying is found in the Yellow River watershed, with slight wetting in north and south China. The TP and India become drier. The precipitation changes have regional characteristics with seasonal variations as well, which might relate to the hydrological disasters in China. 
Earth Interactions - Volume 11 (2007) - Paper No. 15 • Page 12
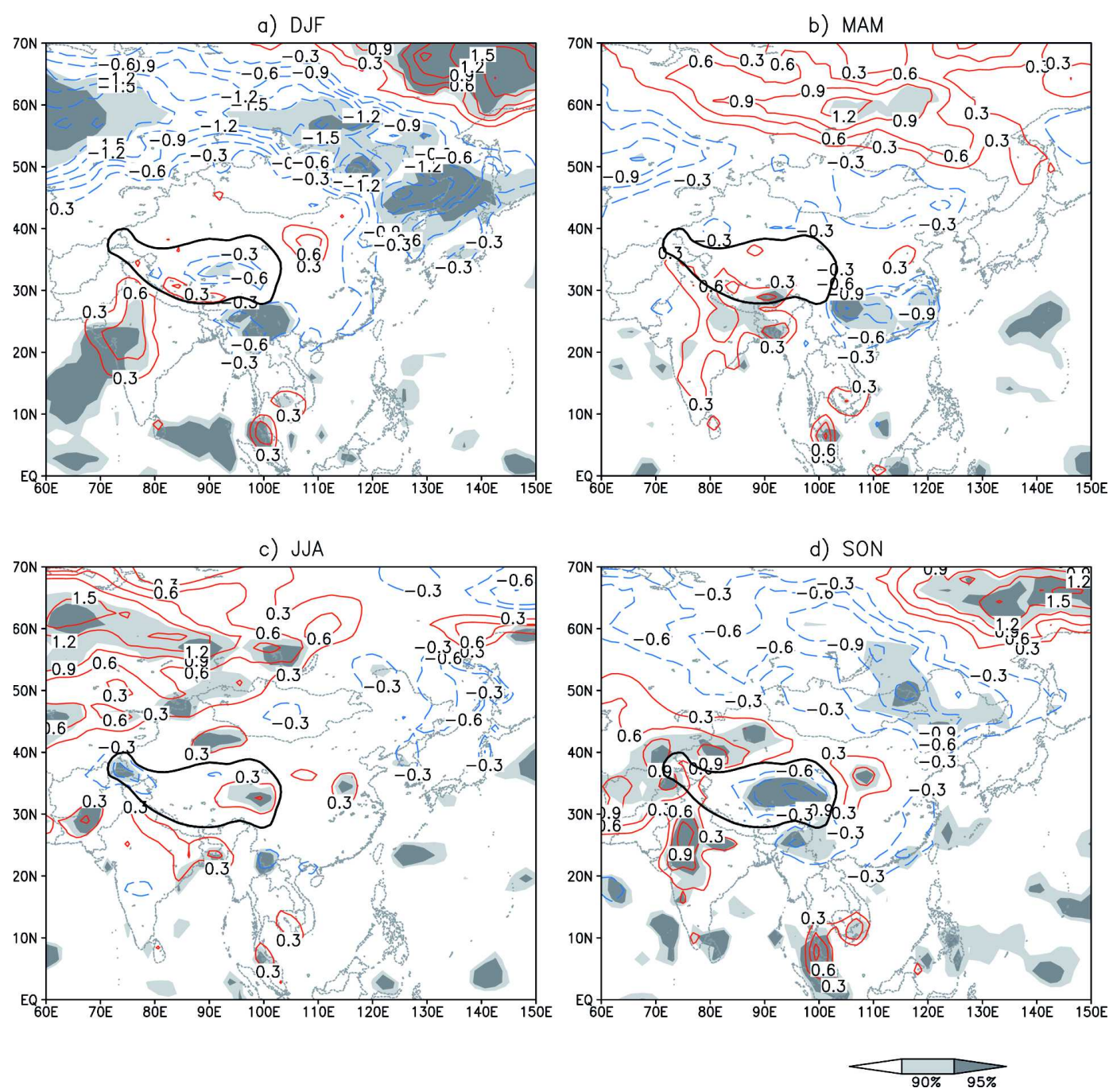

Figure 6. Difference of 10-yr mean seasonal 2-m temperature (unit: $\mathrm{K}$ ) between current and forest scenarios (current minus forest) in the (a) DJF, (b) MAM, (c) JJA, and (d) SON seasons. Statistical significance of $90 \%$ and $95 \%$ is shaded. The black thick contour shows the location of the Tibetan Plateau.

To further demonstrate the influence of deforestation of the SETP on the river discharges, the changes of annual average of surface runoff (precipitation minus evaporation plus snowmelt) are shown in Figure 8. It demonstrates that more surface runoff is available from the deforested area with a maximum value up to $0.8 \mathrm{~mm} \mathrm{day}^{-1}$. This would largely influence the river discharge in the upper reach of the Yangtze River, possibly worsening the flooding situations. Another significant increase of surface runoff is found in northeast China with a maximum value of $0.4 \mathrm{~mm} \mathrm{day}^{-1}$, which might influence several river watersheds including the Liao and Songhua Rivers. Meanwhile, decrease of runoff is found in the middle and lower reaches of the Yellow River with a maximum of $0.8 \mathrm{~mm} \mathrm{day}^{-1}$ in the 

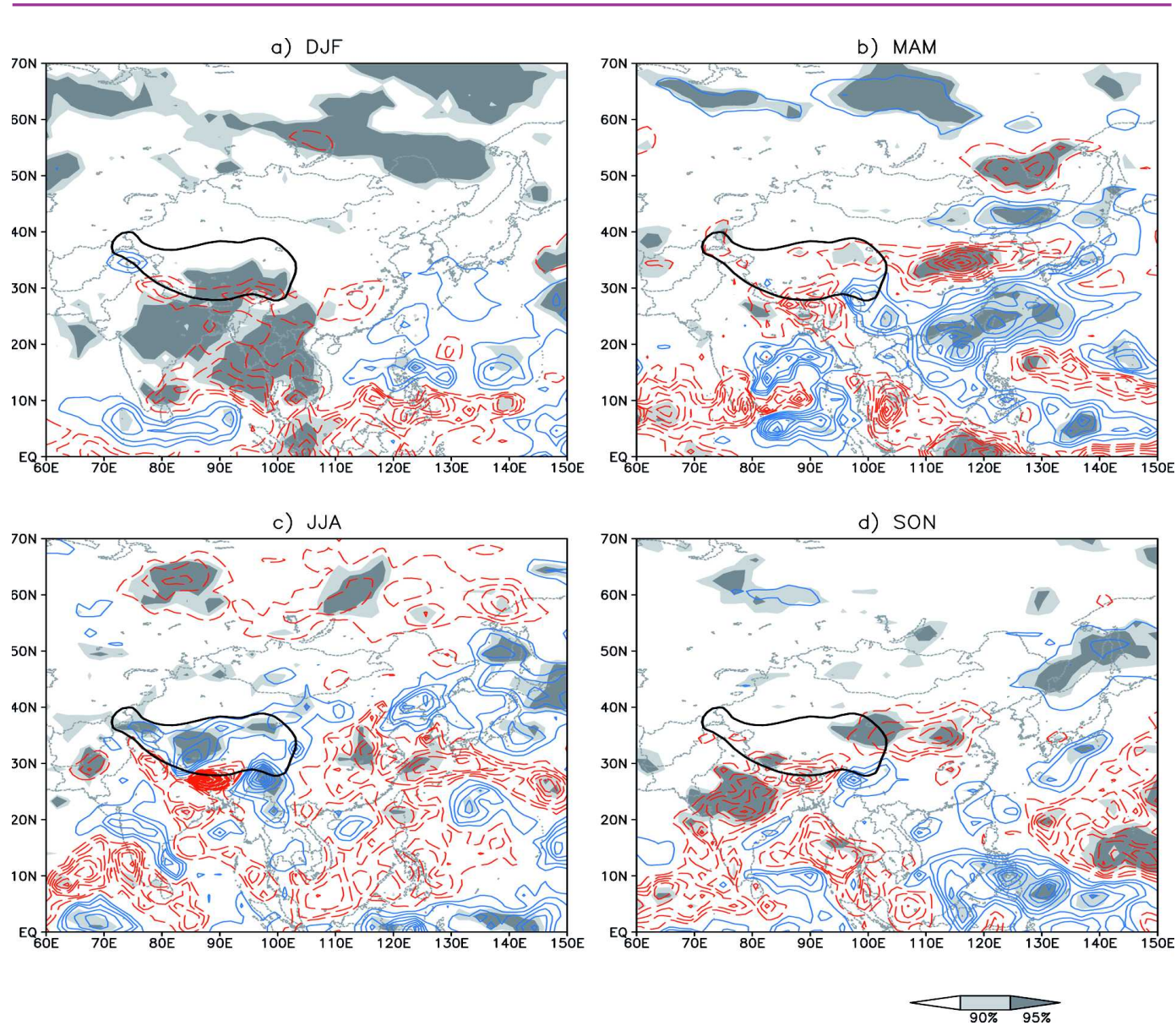

Figure 7. Same as in Figure 6, but for seasonal precipitation with contour interval of $0.2 \mathrm{~mm} \mathrm{day}^{-1}$ (blue for positive values; red for negative ones).

lower reach. That might worsen the drought disaster faced by the livelihood and economics in this region recently. The correlation between deforestation on SETP and the recent hydrological problems in China found in this study highly encourage further studies to validate it.

\section{Discussion and conclusions}

Numerical experiments have been conducted with an atmospheric general circulation model at $1.875^{\circ}$ resolution to investigate the climatic impacts of deforestation in the southeastern Tibetan Plateau, which mainly happened during the second half of the twentieth century. Hydrological impacts on the deforested and downstream areas are studied. Through comparison of the control and forest replacement scenarios, it is found that deforestation has some impact on local and remote climate. The most important hydrological implications can be summarized as follows. 1) Deforestation on the SETP induces decreased transpiration and increased precipitation locally, especially in spring. The TP, as a whole, gets 
Earth Interactions - Volume 11 (2007) - Paper No. 15 • Page 14

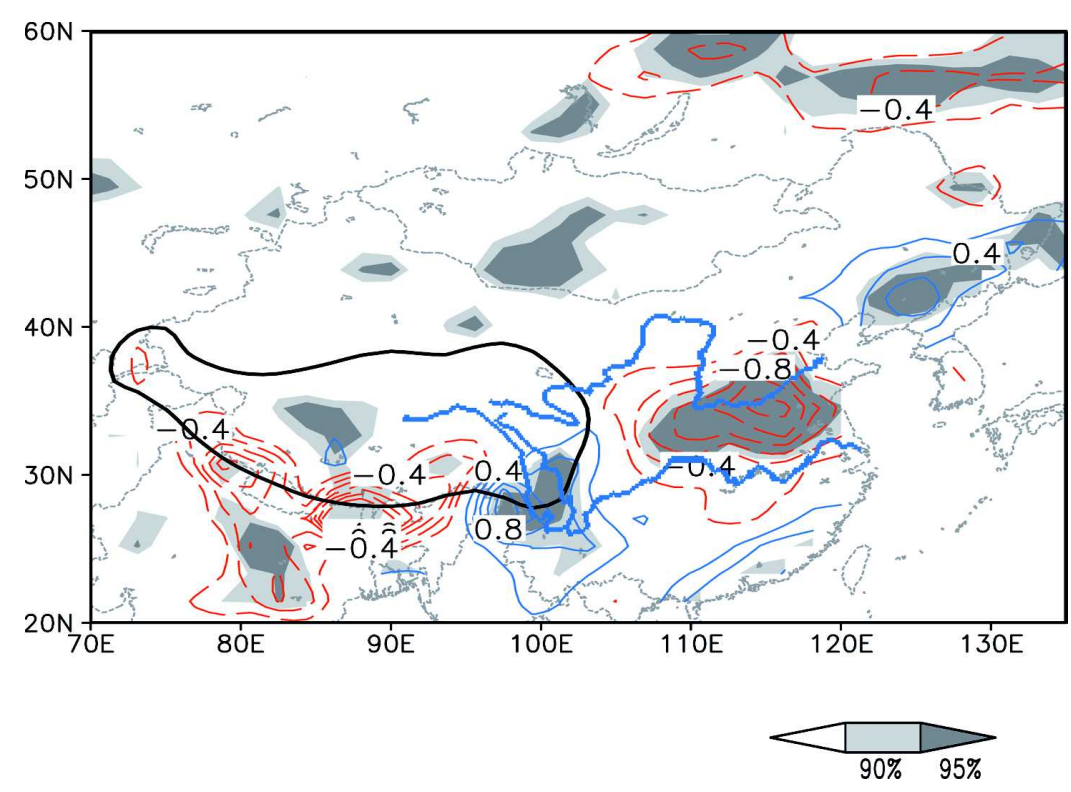

Figure 8. Difference of annually averaged daily surface runoff (unit: $\mathrm{mm} d a y^{-1}$ ) between current and forest scenarios (current minus forest). Statistical significance of $90 \%$ and $95 \%$ is shaded. The black thick contour shows the location of the Tibetan Plateau. Green contour lines show the locations of the (upper) Yellow River and Yangtze River.

warmer and wetter in summer while colder in autumn and winter. These changes might lead to increased runoff into the rivers originating from the TP and possibly worsen the flooding disasters in these rivers. 2) The deforestation on the SETP has a regional impact on the Asian climate. Precipitation changes downstream of the SETP have distinct seasonal and spatial characteristics. The drying along the middle and lower reaches of the Yellow River is significant for almost the whole year and might have worsened the recent drought problems in this area.

The TP plays an important role in the Northern Hemispheric circulation (e.g., Ye and Gao 1979), possibly suggesting the global-scale response to the land surface changes on it. Our model suggests a global-scale response to the deforestation at the SETP, however, with little statistical significance except the Asian area discussed above (figures not shown) similar to that in the case study of anthropogenic land cover changes on the Tibetan Plateau (CUI2006). Findell et al. (Findell et al. 2006) found very little statistically significant response beyond the Tropics to complete tropical deforestation in their long time period model integrations, which neglected the teleconnections found in the previous studies of the tropical deforestation (Zhang et al. 1996; Mabuchi et al. 2005a; Mabuchi et al. 2005b; Avissar and Werth 2005). It is worth performing a model integration with a longer time period than $10 \mathrm{yr}$, as in this study, especially to test the statistical significance. To tackle the model uncertainties on the Tibetan Plateau, ensemble experiments like AMIP (Gates et al. 1999) or the Climate Model Intercomparison Project (CMIP; Covey et al. 2003) with more models should also be encouraged.

The heterogeneous land surface characteristics and complex orographic varia- 
Earth Interactions • Volume 11 (2007) • Paper No. 15 • Page 15

tions on the Tibetan Plateau may exert significant local weather systems. This needs to be tackled with a regional or mesoscale model by improvement of the parameterization scheme together with the efforts of the international measurement campaigns, like the Global Energy and Water-Cycle Experiment (GEWEX) Asian Monsoon Experiment (GAME) within the World Climate Research Program (WCR), called GAME-Tibet (available online at http://monsoon.t.u-tokyo.ac.jp/ tibet), and the Coordinated Enhanced Observing Period (CEOP) Asia-Australia Monsoon Project (CAMP), called CAMP-Tibet (available online at http://www. ceop.net). In this study, a cooling due to increasing surface albedo of deforestation was not found like at other places (Myhre and Myhre 2003; Hales et al. 2004). With simplified land surface atmosphere interaction processes applied in a GCM, like ECHAM5, it is hard to justify such changes. Hopefully, application of the high-resolution regional climate models (Cui et al. 2007) can help to contribute to this aspect. The interdisciplinary research of ecosystem changes on the Tibetan Plateau is still in its infancy and, therefore, needs more contribution from the international community.

Acknowledgments. We thank two anonymous reviewers for making many useful comments and suggestions for improvements in this manuscript. We also thank Dr. Stefan Hagemann at MPI for his suggestions and internal reviewing of an early version of this manuscript. We are grateful to Dr. Andy Plater for his help with the English grammar. This study is supported by the ENTEAM project under the Chinese Academy Science and Max Planck Society (CAS-MPG) cooperation framework. The simulations have been carried out at the German Climate Computer Center (DKRZ).

\section{References}

Avissar, R., and D. Werth, 2005: Global hydroclimatological teleconnections resulting from tropical deforestation. J. Hydrometeor., 6, 134-145.

— , P. L. S. Dias, M. A. F. S. Dias, and C. A. Nobre, 2002: The Large-Scale BiosphereAtmosphere Experiment in Amazonia (LBA): Insights and future research meeds. J. Geophys. Res., 107, 8086, doi:10.1029/2002JD002704.

Baidya Roy, S., and R. Avissar, 2002: Impact of land use/land cover change on regional hydrology in Amazonia. J. Geophys. Res., 107, 8037, doi:10.1029/2000JD000266.

Bengtsson, L., K. Arpe, E. Roeckner, and U. Schulzweida, 1996: Climate predictability experiments with a general circulation model. Climate Dyn., 12, 261-278.

Betts, R. A., 2000: Offset of the potential carbon sink from boreal forestation by decreases in surface albedo. Nature, 408, 187-190.

Bonan, G. B., 1997: Effects of land use on the climate of the United States. Climatic Change, 37, 449-486.

Braeuning, A., and B. Mantwill, 2004: Summer temperature and summer monsoon history on the Tibetan Plateau during the last 400 years recorded by tree rings. Geophys. Res. Lett., 31, L24205, doi:10.1029/2004GL020793.

Broccoli, A. J., and S. Manabe, 1992: The effect of orography on midlatitude Northern Hemisphere dry climates. J. Climate, 5, 1181-1201.

Brovkin, V., S. Sitch, W. von Bloh, M. Claussen, E. Bauer, and W. Cramer, 2004: Role of land cover changes for atmospheric $\mathrm{CO}_{2}$ increases and climate change during the last 150 years. Global Change Biol., 10, 1-14. 


\section{Earth Interactions • Volume 11 (2007) • Paper No. 15 • Page 16}

Charney, J. G., 1975: Dynamics of deserts and droughts in the Sahel. Quart. J. Roy. Meteor. Soc., 101, 193-202.

Costa, M. H., and J. A. Foley, 2000: Combined effects of deforestation and double atmospheric $\mathrm{CO}_{2}$ concentrations on the climate of Amazonia. J. Climate, 13, 18-34.

Covey, C., K. M. AchutaRao, U. Cubasch, P. Jones, S. J. Lambert, M. E. Mann, T. J. Philips, and K. E. Taylor, 2003: An overview of results from the Coupled Model Intercomparison Project (CMIP). Global Planet. Change, 37, 103-133.

Cui, X. F., H.-F. Graf, B. Langmann, W. Chen, and R. H. Huang, 2006: Climate impacts of anthropogenic land use changes on the Tibetan Plateau. Global Planet. Change, 54, 33-56.

_ B. Bangmann, and H.-F. Graf, 2007: Summer monsoonal rainfall simulation on the Tibetan Plateau with a regional climate model using a one-way double-nesting system. Sci. Online Lett. Atmos., 3, 49-52.

Duemenil Gates, L., and S. Liess, 2001: Impacts of deforestation and afforestation in the Mediterranean region as simulated by the MPI atmospheric GCM. Global Planet. Change, 30, 309-328.

Fang, J., A. Chen, C. Peng, S. Zhao, and L. Ci, 2001: Changes in forest biomass carbon storage in China between 1949 and 1998. Science, 292, 2320-2322.

Findell, K. L., T. R. Knutson, and P. C. D. Milly, 2006: Weak simulated extratropical response to complete tropical deforestation. J. Climate, 19, 2835-2850.

Ganzeveld, L., and J. Lelieveld, 2004: Impact of Amazonian deforestation on atmospheric chemistry. Geophys. Res. Lett., 31, L06105, doi:10.1029/2003GL019205.

Gates, W. L., and Coauthors, 1999: An overview of the results of the Atmospheric Model Intercomparison Project (AMIP I). Bull. Amer. Meteor. Soc., 80, 29-55.

Govindasamy, B., P. B. Duffy, and K. Caldeira, 2001: Land use changes and Northern Hemisphere cooling. Geophys. Res. Lett., 28, 291-294.

Hagemann, S., 2002: An improved land surface dataset for global and regional climate models. Rep. 336, Max-Planck-Institut fuer Meteorologie, Hamburg, Germany, 10 pp. [Available online at http://www.mpimet.mpg.de.]

— K. Arpe, and E. Roeckner, 2006: Evaluation of the hydrological cycle in the ECHAM5 model. J. Climate, 19, 3810-3827.

Hales, K., J. D. Neelin, and N. Zeng, 2004: Sensitivity of tropical land climate to leaf area index: Role of surface conductance versus albedo. J. Climate, 17, 1459-1473.

Henderson-Sellers, A., and V. Gornitz, 1984: Possible climatic impacts of land cover transformation, with particular emphasis on tropical deforestation. Climatic Change, 6, 231-258.

Houghton, R. A., and J. L. Hackler, 2003: Sources and sinks of carbon from land-use change in China. Global Biogeochem. Cycles, 17, 1034, doi:10.1029/2002GB001970.

Klein Goldewijk, K., 2001: Estimating global land use change over the past 300 years: The HYDE database. Global Biogeochem. Cycles, 15, 417-433.

Linderman, M., P. Rowhani, D. Benz, S. Serneels, and E. F. Lambin, 2005: Land-cover change and vegetation dynamics across Africa. J. Geophys. Res., 110, D12104, doi:10.1029/ 2004JD005521.

Liu, J., H. Tian, M. Liu, D. Zhuang, J. M. Melillo, and Z. Zhang, 2005: China's changing landscape during the 1990s: Large-scale land transformation estimated with satellite data. Geophys. Res. Lett., 32, L02405, doi:10.1029/2004GL021649.

Ma, Y., L. Zhong, Z. Su, H. Ishikawa, M. Menenti, and T. Koike, 2006: Determination of regional distributions and seasonal variations of land surface heat fluxes from Landsat-7 Enhanced Thematic Mapper data over the central Tibetan Plateau area. J. Geophys. Res., 111, D10305, doi:10.1029/2005JD006742.

Mabuchi, K., Y. Sato, and H. Kida, 2005a: Climatic impact of vegetation change in the Asian tropical region. Part I: Case of the Northern Hemisphere summer. J. Climate, 18, 410-428.

,-- , and $-2005 \mathrm{~b}$ : Climatic impact of vegetation change in the Asian tropical region. 
Earth Interactions • Volume 11 (2007) • Paper No. 15 • Page 17

Part II: Case of the Northern Hemisphere winter and impact on the extratropical circulation. J. Climate, 18, 429-446.

Miehe, G., S. Miehe, K. Koch, and M. Will, 2003: Sacred forests in Tibet. Mt. Res. Dev., 23, 324-328.

Myhre, G., and A. Myhre, 2003: Uncertainties in radiative forcing due to surface albedo changes caused by land-use changes. J. Climate, 16, 1511-1524.

Negri, A. J., R. F. Adler, L. Xu, and J. Surratt, 2004: The impact of Amazonian deforestation on dry season rainfall. J. Climate, 17, 1306-1319.

Niu, T., L. Chen, and Z. Zhou, 2004: The characteristics of climate change over the Tibetan Plateau in the last 40 years and the detection of the climate jumps. Adv. Atmos. Sci., 21, 193-203.

Pan, Z., T. Eugene, M. Segal, and R. Arritt, 1999: Simulation of potential impacts of man-made land use changes on U.S. summer climate under various synoptic regimes. J. Geophys. Res., 104, 6515-6528.

Roeckner, E., and Coauthors, 2003: The atmospheric general circulation model ECHAM5. Part I: Model description. Rep. 349, Max-Planck-Institut fuer Meteorologie, Hamburg, Germany, 5-6. [Available online at http://www.mpimet.mpg.de.]

— the ECHAM5 atmosphere model. J. Climate, 19, 3771-3791.

Roesch, A., and E. Roeckner, 2006: Assessment of snow cover and surface albedo in the ECHAM5 general circulation model. J. Climate, 19, 3828-3844.

Sen, O. L., Y. Wang, and B. Wang, 2004: Impact of Indochina deforestation on the East Asian summer monsoon. J. Climate, 17, 1366-1380.

Sharma, K. P., C. J. Vorosmarty, and B. Moore III, 2000: Sensitivity of the Himalayan hydrology to land-use and climate changes. Climatic Change, 47, 117-139.

Shukla, J., C. Nobre, and P. J. Sellers, 1990: Amazon deforestation and climate change. Science, 247, 1322-1325.

Sitch, S., V. Brovkin, W. von Bloh, D. Van Vuuren, B. Eickhout, and A. Ganopolski, 2005: Imapcts of future land cover changes on atmospheric $\mathrm{CO}_{2}$ and climate. Global Biogeochem. Cycles, 19, GB2013, doi:10.1029/2004GB002311.

Snyder, P. K., J. A. Foley, M. H. Hitchmann, and C. Delire, 2004: Analyzing the effects of complete tropical forest removal on the regional climate using a detailed three-dimensional energy budget: An application to Africa. J. Geophys. Res., 109, D21102, doi:10.1029/ 2003JD004462.

Studley, J., 1999: Forests and environmental degradation in SW China. Int. For. Rev., 1, 260-265.

U.S. Geological Survey, cited 2001: Global land cover characteristics data base version 2.0. [Available online at http://edcdaac.usgs.gov/glcc/globdoc2_0.html.]

van den Hurk, B. J. J. M., P. Viterbo, and S. O. Los, 2003: Imapct of leaf area index seasonality on the annual land surface evaporation in a global circulation model. J. Geophys. Res., 108, 4191, doi:10.1029/2002JD002846.

von Storch, H., and F. W. Zwiers, 1999: Statistical Analysis in Climate Research. Cambridge University Press, 113 pp.

Webster, P. J., V. O. Magaña, T. N. Palmer, J. Shukla, R. A. Tomas, M. Yanai, and T. Yasunari, 1998: Monsoons: Processes, predictability, and the prospects for prediction. J. Geophys. Res., 103, 14 451-14 510.

Werth, D., and R. Avissar, 2002: The local and global effects of Amazon deforetation. J. Geophys. Res., 107, 8087, doi:10.129/2001JD000717.

Xue, Y., H. H. Juang, W. P. Li, S. Prince, R. DeFries, Y. Jiao, and R. Vasic, 2004: Role of land surface processes in monsoon development: East Asia and West Africa. J. Geophys. Res., 109, D03105, doi:10.1029/2003JD003556.

Ye, D., and Y. Gao, 1979: The Meteorology of the Qinghai-Xizang (Tibet) Plateau (in Chinese). Sciences Press, 278 pp. 
Earth Interactions - Volume 11 (2007) • Paper No. 15 • Page 18

Zhang, H., K. McGuffie, and A. Henderson-Sellers, 1996: Imapcts of tropical deforestation. Part II: The role of large-scale dynamics. J. Climate, 9, 2498-2521.

— A. Hender-Sellers, and K. McGuffie, 2001: The compounding effects of tropical deforestation and greenhouse warming on climate. Climatic Change, 49, 309-338.

Zhang, P., G. Shao, G. Zhao, D. C. Le Master, G. R. Parker, J. B. Dunning Jr., and Q. Li, 2000: China's forest policy for the 21th century. Science, 288, 2135-2136.

Earth Interactions is published jointly by the American Meteorological Society, the American Geophysical Union, and the Association of American Geographers. Permission to use figures, tables, and brief excerpts from this journal in scientific and educational works is hereby granted provided that the source is acknowledged. Any use of material in this journal that is determined to be "fair use" under Section 107 or that satisfies the conditions specified in Section 108 of the U.S. Copyright Law (17 USC, as revised by P.IL. 94-553) does not require the publishers' permission. For permission for any other form of copying, contact one of the copublishing societies. 
Copyright of Earth Interactions is the property of American Meteorological Society and its content may not be copied or emailed to multiple sites or posted to a listserv without the copyright holder's express written permission. However, users may print, download, or email articles for individual use. 